\title{
A relevância do estudo sobre psicogênese da língua escrita para formação de professores alfabetizadores
}

\author{
The relevance of the study on Psychogenesis of Written Language for the Formation of Literacy
}

\section{Teachers}

\section{La relevancia del estudio sobre la psicogénesis del lenguaje escrito para la formación de profesores de alfabetización}

\section{Resumo}

O presente trabalho buscou discutir sobre a importância da alfabetização e de professores especializados. O foco principal é a concepção da Psicogênese da Língua Escrita fundamentada pelas autoras Emilia Ferreiro e Ana Teberosky, que tiveram como referência para sua obra a teoria construtivista de Jean Piaget. Faz-se uma reflexão sobre a relevância da concepção para entender o processo de aprendizagem de leitura e escrita e sua grande repercussão conceitual para a alfabetização brasileira. Para o desenvolvimento deste estudo, realizamos pesquisa bibliográfica. Serão apresentados os aspectos comuns encontrados no percurso e nos processos individuais da base alfabética escrita e serão pontuados os períodos presentes durante esse percurso. Buscamos esclarecer a importância do professor como mediador de todo este processo, que traz consigo muitos papéis: conhecedor da língua, observador da escrita, organizador de boas situações de aprendizagem e mediador entre o sujeito e o objeto de conhecimento. Para que isso seja possível, o professor precisa ter instrumentos para detectar com clareza o que seus alunos já sabem e o que eles ainda não sabem sobre o que se pretende ensinar, no caso desta pesquisa a escrita. Conclui-se então que é de extrema fundamental importância a formação continuada e disposição do professor para estudar e construir sua competência profissional.

Palavras-chave: Leitura; Escrita; Ensino; Aprendizagem.

\begin{abstract}
People with visual disabilities in carrying out tasks such as getting around and picking up objects face greater difficulties in supermarkets. In this respect it was noticed the lack of accessibility makes consumers with visual impairment choose to buy over the internet. In this context, we sought to explore and discuss Assistive Technology and its viability in supermarkets. The object of this work is the development of a mobile application for the supermarket, where it uses geolocation within the establishment as a means of locomotion and guidance within the supermarket, with the help of the beacon, the technology will inform the consumer where the desired product is located, in principle. what section you are in, so you can guide to the destination where the product is located. And with the Near Field Communication tags, the consumer who has visual limitation as the elderly will be able to identify which product they are taking, having knowledge: which brand, its weight, price, expiration date. For the development of the project the Ionic framework was chosen, the application has the human voice recognition mechanism, in which the visually impaired person will inform the desired product.
\end{abstract}

Keywords: Reading; Writing; Teaching; Learning. 


\begin{abstract}
Resumen
El presente trabajo buscó discutir la importancia de la alfabetización y los profesores especializados. El eje principal es la concepción de la Psicogénesis del Lenguaje Escrito, fundada por las autoras Emilia Ferreiro y Ana Teberosky, quienes utilizaron la teoría constructivista de Jean Piaget como referencia para su trabajo. Se reflexiona sobre la relevancia de la concepción para comprender el proceso de aprender a leer y escribir y su gran repercusión conceptual para la alfabetización brasileña. Para el desarrollo de este estudio, realizamos una búsqueda bibliográfica. Se presentarán los aspectos comunes encontrados en el camino y en los procesos individuales de la base alfabética escrita y se puntuarán los períodos presentes durante este camino. Buscamos aclarar la importancia del docente como mediador de todo este proceso, que trae consigo múltiples roles: experto en lenguaje, observador de la escritura, organizador de buenas situaciones de aprendizaje y mediador entre el sujeto y el objeto de conocimiento. Para que esto sea posible, el docente necesita contar con instrumentos que detecten claramente lo que sus alumnos ya saben y lo que aún no saben sobre lo que se pretende enseñar, en el caso de esta investigación, la escritura. Por lo tanto, se concluye que la educación continua y la voluntad de los docentes para estudiar y desarrollar su competencia profesional es extremadamente importante.
\end{abstract}

Palabras clave: Lectura; Escribir; Enseñar; Aprendiendo.

\title{
1. Introdução
}

A razão da escolha desse tema é a de mostrar o porquê o professor que irá trabalhar com a alfabetização, necessita ter um conhecimento sobre as ideias trazidas pela psicogênese da língua escrita, acrescentando e contribuindo na estruturação de novos conhecimentos que serão úteis no momento de identificar os aspectos de uma escrita comum, que ao observar de maneira superficial não haverá hipótese a respeito da escrita.

Nos dias atuais existem muitas teorias de aprendizagem, que buscam entender e esclarecer sobre como uma criança aprende o sistema de escrita, uma dessas teorias é a pesquisa realizada por Ferreiro e Teberosky (1999), intitulada Psicogênese da Língua Escrita teve como ponto de partida a epistemologia de Jean Piaget, que contribuiu para uma visão diferente a partir de como se constrói o conhecimento, em uma visão construtivista (Kaufman et al., 1998).

Pontua as autoras sobre o sujeito que conhecemos através da teoria de Piaget:

É aquele que procura ativamente compreender o mundo que o rodeia e trata de resolver as interrogações que este mundo provoca. Não é um sujeito o qual espera que alguém que possui um conhecimento o transmita a ele por um ato de benevolência. É um sujeito que aprende basicamente através de suas próprias ações sobre os objetos do mundo e que constrói suas próprias categorias de pensamento ao mesmo tempo em que organiza seu mundo (Ferreiro; Teberosky, 1999, p. 29).

Enfatizam a teoria de Piaget como uma teoria geral dos processos de aquisição de conhecimento:

A teoria de Piaget não é uma teoria particular sobre um domínio particular, mas sim um marco teórico de referência, muito mais vasto, que nos permite compreender de uma maneira nova qualquer processo de aquisição de conhecimento (Ferreiro; Teberosky, 1999, p.31).

Com baseamento nisso, as autoras Ferreiro e Teberosky (1999), que são psicolinguísticas argentinas, iniciaram em 1974 uma investigação que deu origem a psicogênese, permitindo compreender novas maneiras no processo de aquisição de conhecimento.

Então a psicogênese parte da concepção que a aquisição do conhecimento se baseia na atividade do sujeito em interação com o objeto de conhecimento, pois, nenhuma aprendizagem conhece um ponto de partida absoluto, "em termos práticos, isso significa que o ponto de partida de toda aprendizagem é o próprio sujeito, e não o conteúdo a ser abordado", (Ferreiro; Teberosky, 1999, p.32).

Desse modo, é descrito coerentemente o que é comum a todos os processos individuais de alfabetização, uma descrição detalhada do percurso que cada indivíduo faz em contato com a língua escrita. A partir da década de 80, começaram 
a aparecer os resultados das pesquisas que trouxeram novas concepções e ideias sobre o processo de aquisição da escrita pela criança.

De acordo com Weisz (1988, p. 1), a Psicogênese trata-se de:

Uma teoria, isto é, um modelo explicativo do real. Uma tentativa de descrever coerentemente o que é comum a todos os processos individuais de alfabetização. Uma descrição mapeadora do percurso que cada indivíduo faz em seu processo partícula de aquisição da base alfabética da escrita.

Uma das contribuições trazidas por essa concepção é a que a escrita não é um produto escolar e sim, um objeto cultural, que é resultado do esforço coletivo de todos os envolvidos. Tanto que os resultados das pesquisas, trazidas pelas autoras da Psicogênese resultaram em uma reviravolta no processo de alfabetização da época quando foi divulgada (Ferreiro; Teberosky, 1999).

Com a divulgação da Psicogênese ocorreu uma revolução conceitual a respeito da alfabetização por ter como consequência uma "mudança" no eixo no qual era representado, relacionando-se com a própria concepção de língua escrita e de alfabetização. Para Ferreiro (apud Mello, 2003, p. 88): "a língua escrita deve ser entendida como um sistema de representação da linguagem, concepção que se opõe aquela que a língua escrita é considerada como codificação e decodificação de linguagem".

Conseguintemente, Mello (2003, p. 88) pontua:

Ferreiro se opõe ao conceito de alfabetização entendido como a aprendizagem de duas técnicas diferentes (codificar e decodificar a língua escrita), em que o professor é o único informante autorizado. Ferreiro defende, então, o conceito de alfabetização que vai a sentido contrário, já que a considera como o processo de aprendizagem da língua escrita. Essa aprendizagem, considerada, também, aprendizagem conceituall, dá-se por meio da interação entre o objeto de conhecimento (a língua escrita) e o sujeito cognoscente (que quer conhecer).

A psicogênese da língua escrita descreve como o aluno adquiriu os conceitos e habilidades de ler e escrever, explicando que a aquisição segue um percurso parecido com aquele que a humanidade percorreu ate chegar ao sistema alfabético. "O aluno, na fase pré-silábica do caminho que percorre até enfatizar-se, ignora que a palavra escrita representa a palavra falada, e desconhece como essa representação se processa. Ele precisa, então,

responder a duas questões: o que a escrita representa e o modo de construção dessa representação" (Mendonça; Mendonça, 2011, p.39).

Ferreiro e Teberosky (1999, p 31) afirmam:

A concepção de aprendizagem (entendida como um processo de obtenção de conhecimento) inerente à psicologia genética supõe, necessariamente, que existam processos de aprendizagem do sujeito que não dependem soa métodos (processos que, poderíamos dizer passar "através" dos métodos).

Para que toda essa concepção seja construída são necessários interações, onde o aprendiz constrói hipóteses a respeito da escrita, percorrendo um caminho que é representado por níveis, que são denominados como: Pré-silábico, silábico, silábicoalfabético e alfabético, que estarão presentes durante todo o processo de aquisição da língua escrita.

Fazem parte desse processo os chamados "erros construtivos", que são fundamentais para construir os conceitos necessários a compreensão de todo o sistema alfabético, devendo o educador compreender o processo de construção para poder intervir de forma correta e competente durante a aprendizagem de seus alunos. Entendendo que os erros são essenciais para as novas concepções, não devendo ser considerados como erros, mais sim, como futuras transformações.

Portanto, Segundo Mendonça e Mendonça (2011, p. 41): 
O referencial teórica da Psicogênese da Língua Escrita, leva-nos a entender que na escrita é uma reconstrução real e inteligente, com um sistema de representação historicamente construído pela humanidade e pela criança que se alfabetiza, embora não reinvente as letras e os números. A criança alfabetiza a si mesma e inicia essa aprendizagem antes mesmo de entrar na escola, e seus efeitos prolongam-se após a ação pedagógica.

Por isso, é preciso que o professor tenha os conhecimentos básicos sobre essa concepção que descreve o aprendiz, formulando hipóteses a respeito da escrita, mostrando o caminho que pode ser representado na construção da escrita, seguindo os níveis: pré-silábico, silábico, silábico-alfabético, alfabético.

Todo o processo de alfabetização exige um professor empenhado com o papel de mediador entre a escrita e seu educando, para Ferreiro (1996 apud Santos, 2013), não basta que o professor saiba apenas identificar o nível de escrita de seus alunos, mais sim, entender a caracterização de cada período.

É preciso também que o professor estude e converse com seus colegas de serviço, construindo para si mesmo os conhecimentos disponíveis hoje, sobre hipóteses e idéias que tem as crianças assim, construindo em seu esforço o aprendizado da leitura e escrita. Quando $\square$ processo não acontece da forma adequada, há alguns equívocos como pensar que silábicos são alunos que leem de forma silabada, ou os pré-silábicos alunos que escrevem com muitos erros de ortografia (Ferreiro, 2003).

Não é possível descobrir o que os alunos sabem, sem um conhecimento mínimo sobre a psicogênese da língua escrita, é fundamental no processo ter anotado em algum lugar especifico um espaço para todos seus alunos, tendo anotados todos os avanços, observações, idéias sobre como funciona o sistema de escrita, ao longo de todo ano escolar para poder ter uma visão de todo processo (Ferreiro, 2003).

Com a presença dos conhecimentos trazidos pela psicogênese, é possível identificar e caracterizar o que a criança já entende sobre a língua escrita, possibilitando a exploração de estratégias para ajudar o aluno a avançar e criar hipóteses sobre como utilizar à escrita. Não é possível que o professor identifique o que seus alunos sabem mediante a visualização de suas escritas se tratando das hipóteses, sem um conhecimento mínimo sobre o assunto, visto que o conhecimento trazido por esta teoria é fundamental para poder observar cada detalhe com um entendimento adequado.

O papel realizado pelo professor de alfabetização é de extrema importância em todo o processo percorrido durante o tempo de aprendizagem de qualquer criança, por isso, é ideal que os conhecimentos sejam aprofundados para que não haja dúvidas de como criar situações produtivas e significativas, entre a criança e o objeto de conhecimento que no caso, seria a alfabetização. Como afirma Oliveira (2011), a observação é um dos principais pontos dentro de uma sala de aula, para que haja a percepção de dificuldades e a oportunidade de ajudar quando preciso, o professor observador é qual planeja suas intervenções sempre com a intenção de contribuir para a construção de conhecimentos.

Segundo Weisz (2000, p.94):

Como um observador privilegiado das ações do aprendiz, o professor tem condições de avaliar o tempo todo, e é essa avaliação que lhe dá indicadores para sustentar sua intervenção, mas isso é diferente de planejar e implementar uma atividade para avaliar a aprendizagem.

O grande problema enfrentando pela maioria dos educadores é não saber como ensinar a língua escrita, pela falta de conhecimento e de aprendizagem sobre o assunto, isso acaba por dificultar ainda mais o processo, pois se o professor tiver o conhecimento correto pode ajudar e garantir que aquela escrita futuramente se transformará em uma escrita comum, trabalhando e utilizando de recursos para que isso seja possível, por isso, o professor deve: "criar situações que permitam ao aluno vivenciar os usos sociais que se fazem da escrita, as características dos diferentes gêneros textuais, a linguagem adequada a diferentes contextos comunicativos" (Fernandes, 2008, p.18 apud Oliveira, 2011, p.12622).

A pesquisa de Ferreiro e Teberosky (1999) trouxeram muitas contribuições para a alfabetização, entre elas, a necessidade de uma formação teórica do professor para ter clareza dos processos que envolvem a apropriação do sistema de 
escrita, revelando a importância que a formação do professor tem para o desenvolvimento de práticas alfabetizadoras.

Portanto, este trabalho procura discutir os problemas encontrados durante o processo de alfabetização, analisando os métodos, atividades que podem ser aplicadas e que podem ser usados para que o professor possa intervir no processo de aquisição do aluno por meio de um planejamento envolvendo todas as possibilidades para o avanço, assim, construindo o conhecimento através da percepção própria, ajudando na diminuição do fracasso escolar, mostrando que não há incapacidade de aprender, e sim, maneiras diferentes de se identificar os momentos e talvez corrigi-los da maneira mais coerente possível.

\section{Metodologia}

Este estudo será baseado em informações bibliográficas e seu foco principal será o livro de Emília Ferreiro e Ana Teberosky (1999): “A Psicogênese da Língua Escrita”, trazendo análises sobre a aquisição da escrita alfabética e também haverá a utilização de artigos científicos (encontradas no site acervo digitais, entre outros), com uma busca de acrescentar informações coerentes para pontuar a importância da formação docente para a alfabetização, para que o professor possa requerer de estratégias e saiba como se contrapor nas horas de dificuldades e consiga planejar atividades para que seus alunos avancem no processo de aquisição da língua escrita de forma coerente com o processo percorrido.

\section{Resultados e Discussões}

Esta pesquisa tem como ponto principal a alfabetização, trazendo as ideias de Ferreiro e Teberosky (1999) durante seu percurso. São apresentados aspectos importantes que esses estudos trouxeram para uma mudança no processo de aquisição da língua escrita que antigamente os métodos utilizados eram tradicionais, no qual o professor apenas transmitia os conhecimentos para os alunos, utilizava-se da memorização de sons e decifração e a junção de sílabas simples (Duarte; Rossi; Rodrigues, 2008).

\subsection{Breve histórico da alfabetização}

A história da alfabetização divide-se em três grandes períodos como apresenta Araújo (1996 apud Mendonça, 2000). O primeiro inclui a Antiguidade e a Idade Média em que predominava o método da soletração; o segundo iniciou-se por uma revolta contra o método da soletração entre os séculos XVI e XVIII, até a década de 1960 e foi marcado pela criação dos métodos sintéticos e analíticos e o terceiro período foi marcado pelo questionamento da necessidade de associar os sinais gráficos da escrita aos sons da fala, para que assim houvesse o aprendizado da leitura.

O terceiro período citado acima foi muito questionado, por trabalhar apenas a função da escrita, não se importando com conhecimentos específicos que seriam indispensáveis para se aprender a ler e escrever. Iniciou-se em meados da década de 1980 a divulgação da Psicogênese da Língua Escrita, foi um período marcado pelos questionamentos no desenvolvimento apenas da função social da escrita, dispensando os conhecimentos específicos necessários para o domínio da leitura e da escrita (Araujo, 1996 Apud Mendonça, 2000).

Mendonça (2000) acrescenta um quarto período "reinvenção da alfabetização", que teve como decorrência o fracasso de outras práticas "equivocadas e inadequada", derivadas de tentativas de aplicar a teoria construtivista no processo de alfabetização.

No Brasil, a história da alfabetização tem sua forma mais representada na história dos métodos tradicionais, no final do século XIX a escola assumiu um papel de caráter políticosocial para esclarecer a necessidade da alfabetização. A partir daí, se tem tensas disputas relacionadas com "antigas" e "novas" explicações sobre os problemas encontrados sobre as 16 dificuldades das crianças em ler e escrever, principalmente nas escolas públicas (Mortatti, 2006). 
Apresenta-se, então, as primeiras Cartilhas brasileiras, que foram criadas no fim do século XIX, por professores a partir de suas didáticas, que tinham como base os métodos sintéticos (soletração, fônico e silabação), elas foram usadas por muitas décadas. Em 1876 foi publicada em Portugal a Cartilha Maternal ou Arte de leitura, escrita pelo poeta João de Deus (Bortolini; Miranda; Borssoi, 2015).

Em 1980 o fracasso escolar, com influência da alfabetização, passou a ser questionado e em busca de soluções foi introduzido no Brasil o pensamento construtivista sobre a alfabetização. Teve como base os estudos sobre a Psicogênese da língua escrita, que se deixa de lado o eixo de discussões dos métodos de ensino e coloca-se o foco no processo de aprendizagem da criança (Mortatti, 2011 apud Bortolini; Miranda; Borssoi, 2015).

Em 1990 houve a divulgação do conceito de letramento proposto por Soares (2000 apud Bortolini; Miranda; Borssoi, 2015, p. 24194) como "um estado ou condição de quem não apenas sabe ler e escrever, mas cultiva as práticas sociais que usam a escrita". Segundo esse conceito quando se ensina a ler e escrever, também se aprende um modo de pensar sobre o mundo.

Contudo, neste início de século (XXI) ainda há muitos problemas com o ensino inicial da leitura e escrita, em especial, uma das dificuldades está na ausência de uma "didática" que dê conta dos fracassos escolares neste processo, isso abre espaço, para alguns pesquisadores apresentarem novas propostas de alfabetização baseadas em antigos métodos de alfabetização. Além disso, surgem nas últimas décadas, novos olhares dos pesquisadores sobre a concepção "didática" da alfabetização, são concepções que evidenciam a necessidade de pensar uma educação baseada no contexto social e cultural do indivíduo educando. A alfabetização passa a ser objeto de estudo, com o objetivo de pensar o mundo da escrita de forma reflexiva e crítica (Bortolini; Miranda; Borssoi, 2015, p. 24194).

Neste mesmo ano passou a vigorar no Brasil de acordo com a Lei de Diretrizes e Bases 9394/96 os Parâmetros Curriculares Nacionais, que foram criados com o objetivo de subsidiar as escolas em relação aos conteúdos e práticas de ensino na organização curricular. Com intuito de servir como um manual de orientação para as escolas, caracterizado principalmente como uma ferramenta sobre como proceder às atividades de ensino. De acordo com o Ministério da Educação, os Parâmetros também auxiliariam o professor na execução de seu trabalho, servindo de estimulo e apoio sobre sua prática diária. Os PCN's (1997) defendem a linha Construtivista de ensino, com ênfase na leitura e na língua escrita (Bortolini; Miranda; Borssoi, 2015).

Para Mortatti (2006, p. 03):

Por quase um século, esses esforços se concentraram, sistemática e oficialmente, na questão dos métodos de ensino da leitura e escrita, e muitas foram às disputas entre os que se consideravam portadores de um novo e revolucionário método de alfabetização e aqueles que continuavam a defender os métodos considerados antigos e tradicionais. A partir das duas últimas décadas, a questão dos métodos passou a ser considerada tradicional, e os antigos e persistentes problemas da alfabetização vêm sendo pensados e praticados predominantemente, no âmbito das políticas públicas, a partir de outros pontos de vista, em especial a compreensão do processo de aprendizagem da criança alfabetizada, de acordo com a psicogênese da língua escrita.

Portanto, a criação dos métodos é dividida em métodos sintéticos, que são aqueles que partem das unidades menores para as maiores, apresentam as letras, e ao uni-las formam-se sílabas; unindo as sílabas compõem-se palavras; unindo palavras obtêm-se sentenças e juntando sentenças formam-se textos, onde se encontra o método das cartilhas, que eram muito usadas para se alfabetizar. Já os métodos analíticos que são os que partem de uma palavra com significado, para fazer uma análise em unidades menores, fazem parte também o método de alfabetização de Paulo Freire, mais conhecido como o construtivismo que trouxe grandes idéias que ajudaram a melhorar o ensino (Mendonça; Mendonça, 2011). 


\subsection{Níveis de escrita no processo de aquisição da base alfabética}

Com base nessas ideias, as autoras Ferreiro e Teberosky (1999) afirmam que todas as crianças com a idade para alfabetização passam por quatro fases diferentes para completar seu processo de aquisição da língua escrita: a fase pré-silábica que é aquela em que a criança não relaciona a escrita com o som da língua falada; a fase silábica em que já a atribuição de uma letra para cada som emitido (na fala); a fase silábico-alfabético é onde a uma mistura da aprendizagem anterior com a identificação de sílabas e por fim a fase alfabética, onde já se tem domínio das letras/sílabas que deveram ser utilizadas e na leitura (Moreira, 2014).

Para exemplificar os períodos da aquisição da escrita alfabética: no primeiro período (fase pré silábica), a criança consegue diferenciar o sistema de representação da escrita de outros sistemas de representações. A criança estabelece a diferença entre os desenhos (marcas icônicas) e as letras (não-icônicas), Por conseguinte começam a substituir as marcas figurativas (desenhos) pela escrita, com a utilização de marcas gráficas (Ferreiro; Teberosky, 1999).

Para Ferreiro (1996 apud Duarte; Rossi; Rodrigues, 2008), a leitura e a escrita são sistemas que são aprendidos com o tempo, não é algo que seja pronto e acabado e sim, que tem seu tempo para ser entendido, e durante todo o tempo levado para que haja a concepção da aprendizagem, todas as produções produzidas, mesmo não tendo sentindo (parecendo que não estão certas), devem ser consideradas importantes e vistas de forma compreensiva, observando os aspectos já presentes na escrita.

No primeiro período "a criança consegue diferenciar o sistema de representação da escrita de outros sistemas de representação" (Kaufman et al., 1998, p. 25), havendo diferenciação do desenho e da escrita, sendo designado como diferenciação entre modo de representação icônico e não icônico.

A criança estabelece as diferenças entre marcas gráficas icônicas (como as do desenho, onde se trata de reproduzir em alguma medida a forma do objeto) e as marcas gráficas não icônicas, que são totalmente arbitrárias (mas convencionais) (Vernon, 1986 apud Kaufman et al., 1998, p. 24).

Elas constroem a ideia de que a escrita substitui a realidade que representa e ao desenhar utilizam marcas figurativas desenhando (EX: é uma casa) e não figurativas ao escreverem (EX: disse casa). Podendo ser demonstrado com linhas onduladas ou quebradas, palitos, bolinhas e até letras de pseudoletras (rabiscos que tentam imitar letras), sendo elas, diferentes das escritas com marcas icônicas.

Em nenhum caso a criança tem intenção de controlar a quantidade de marcas que produz (quando estão separadas) ou a longitude do traço (quanto é contínuo). Tampouco há intenção de controlar qual ou quais marcas se utilizam, ou seja, não há ainda desejos de fazer variações na qualidade (KaufmaN et al., 1988, p. 25).

Sendo muito importante destacar que neste momento a criança realiza interpretações globais de sua própria escrita, isto é, faz sinais vagos ou contínuos podendo associá-los a desenhos, sem se preocupar com partes do falado. No segundo período (fase silábica e silábico-alfabética), que se obtém diferenciação no meio do sistema de escrita, primeira são estabelecidas às condições necessárias para que as escritas sejam mais legíveis e posteriormente comecem a diferenciar as escritas entre si (Kaufman et al., 1998).

Neste segundo período exigem duas condições para que as escritas de outros, ou as que eles mesmos produzem, resultem legíveis, ou seja, para que "digam algo". Por um lado (quantitativo), devem ter uma quantidade controlada de marcas; por outro (qualitativo), as marcas empregadas devem ser diferentes (Kaufman et al., 1998, p. 26).

Ferreiro e Teberosky (1986 apud Silva; Farago, 2016), a criança apresenta hipóteses de quantidade (mínimo de letras em cada palavra); hipóteses de variedade nas letras de cada palavra; hipóteses de variedade entre palavras (repertorio de letras); a quantidade de letras esta em função do tamanho do objeto. 
Já para Moreira (2009), o segundo período é caracterizado pela evolução das hipóteses, havendo mais percepção do caráter arbitrário e convencional do sistema de escrita, começando a perceber que a escrita é formada por símbolos e que os símbolos não representam diretamente a realidade. Tendo diferença entre o significante e o significado. Portanto, ainda não consegue saber qual símbolo usar para representar o que ela quer, e quando se pede para escrever, usam-se letras que já conhece (quase sempre as letras do seu nome).

Nessa fase a criança não estabelece relações entre a escrita e a pronuncia, por isso, utiliza-se na escrita de letras aleatoriamente, sem repetições e com o critério de no mínimo e máximo de letras. Outra característica é o "realismo nominal", expressão que é utilizada por Piaget para distinguir a realidade da palavra e do objeto a que se refere (Silva; Farago, 2016).

A partir do momento em que há diferenciação internamente, as crianças podem ter outro trabalho cognitivo: diferenciar outras escrituras entre si, "as condições de legibilidade intrafigurativas se mantêm, mas agora se trata de criar modos sistemáticos de diferenciação entre uma escritura e a seguinte, precisamente para garantir a diferença de interpretação que será atribuída".

Segundo Kaufman et at. (1998, p. 27):

As crianças exploram então critérios que lhes permitem ás vezes, variações sobre a figura central quantitativa (variar a quantidade de letras de uma escritura à outra para obter escrituras diferentes), e às vezes sobre a figura central qualitativa (variar o repertorio de letras que se utilizam de uma escritura à outra; variar a posição das mesmas letras sem modificar a quantidade). A coordenação de ambos os modos de diferenciação (quantitativos e qualitativos) é difícil aqui, como em qualquer domínio da atividade cognitiva.

Neste período, Kaufman et al. (1998, p. 28) afirmam que existem muitas diferenças dentro de uma mesma escrita, que precisam de cuidados ao olhar:

Escrituras com quantidade constante e repertório fixo parcial, escrituras com quantidade variável e repertório fixo parcial, escrituras com quantidade constante e repertório variável, etc., mas todas elas são regidas por critérios alheios à correspondência entre a emissão oral e a produção escrita. As escrituras devem ser diferentes entre si porque os significados são diferentes entre si.

Até aqui a preocupação principal das crianças está em garantir que palavras diferentes devem ser escritas com letras distintas e variações nas quantidades de letras usadas, ainda não relacionam estas diferenças com a sonoridade diferente das palavras, ou seja, não há relação da escrita com a linha sonora da fala.

$\mathrm{O}$ terceiro período (fase alfabética) é quando a criança finalmente consegue diferenciar as escritas, relacionando-as com a pauta sonora da fala (o som ao falar), que é denominado como fonetização da escrita (Kaufman et al., 1998). De acordo com Silva e Farago (2016), a criança já compreende que cada um dos caracteres dá escrita, corresponde a uma analise sonora dos fonemas das palavras que irá escrever, já havendo compreensão do sistema convencional da escrita.

Nesse período, na hipótese silábica Ferreiro e Teberosky (1999) afirmam:

A mudança qualitativa consiste em que: a) se supera a etapa de uma correspondência global entre forma escrita e a expressão oral (recorte silábico do nome); mas, além disso, b) pela primeira vez a criança trabalha claramente com a hipótese de que a escrita representa partes sonoras da fala (Ferreiro; Teberosky, 1999, p. 209).

Ferreiro (1985, p. 13-4 apud Mendonça; Mendonça, 2011, p. 39) enfatiza novas informações:

Vão desestabilizando a hipótese silábica até que a criança tem coragem suficiente para se comprometer em seu novo processo de construção. O período silábico-alfabético marca a transição entre os esquemas prévios em vias de serem abandonados e os esquemas futuros em vias de serem construídos. Quando a criança descobre que a sílaba não pode ser considerada como unidade, mas que ela é, por sua vez, reanalisável em elementos menores, ingressa no último 
passo da compreensão do sistema socialmente estabelecido. E, a partir daí, descobre novos problemas: pelo lado quantitativo, se não basta uma letra por sílaba, também não pode estabelecer nenhuma regularidade duplicando a quantidade de letras por sílaba (já que há sílabas que se escrevem com uma, duas, três ou mais letras); pelo lado qualitativo, enfrentará os problemas ortográficos (a identidade de som não garante a identidade de letras, nem a identidade de letras a de som).

Portanto, afirma-se como a unidade de som que se percebe é a sílaba, a criança inventa a escrita silábica onde cada sílaba é representada por uma letra. Ao escrever eles apresentam problemas nesta hipótese, pois está convencido de que se necessita de mais de uma letra para escrever uma palavra, por isso há dificuldades ao escrever palavras de monossílabas.

Defendendo que, as crianças descobrem a lógica da escrita percebendo a correspondência entre a representação da escrita e as propriedades sonoras das letras, usando assim, ao escrever uma letra para cada emissão sonora.

Kaufman ET al. (1998) afirmam que as crianças tentam fazer corresponder partes da emissão oral com partes da emissão escrita. Irão descobrir qual a classe de recorte da palavra oral corresponde com os elementos da palavra escrita. "Sobre a ideia central do quantitativo isto se expressa no descobrimento de que a quantidade de letras com as quais se vão escrever uma palavra pode colocar-se em correspondência com a quantidade de partes que se reconhecem na emissão oral. Essas "partes" das palavras são inicialmente suas sílabas. Assim se inicia o período silábico que evolui até chegar a uma exigência rigorosa: uma sílaba por letra, sem omitir sílabas nem repetir letras” (Ferreiro, p. 15 apud Kaufman et al., 1998). Porém, num primeiro momento, os objetivos da correspondência silábica costumam ser imperfeitos.

De acordo com Kaufman et al. (1998, p.30), podem surgir determinados conflitos nesse período:

Por outro lado, a escritura silábica pode entrar em contradição com a hipótese de quantidade mínima: no caso de ter que escrever um monossílabo sucede que, segundo a hipótese silábica, só se necessita uma letra, mas por hipótese de quantidade mínima com uma só não se alcança. Por outro lado, a escritura silábica pode entrar em contradição com a hipótese de variedade; por exemplo, as crianças que utilizam valores sonoros vocálicos podem escrever "gato" com "AO" e "pato" com "AO", mas imediatamente esta produção é rechaçada porque já está estabelecido que palavras diferentes devam estar representadas de maneira diferente.

Há crianças que escrevem frases de maneira silábica estrita, utilizando apenas vogais, como por exemplo: "hoje cedo havia sol e agora não" colocam “QIEOAIAOIAOAO”. Ao escreverem dessa forma, fazem questionamentos sobre a escrita dos adultos em comparação com as suas, como: “mas não e assim”, “vocês usam outras”, entendem que seu sistema de escrita é coerente, mas diferente do adulto. É comum nas crianças que escrevem da maneira descrita acima, interpretarem as escritas de outros, fazendo a correspondência com cada sílaba da emissão oral a cada marca da escrita, como por exemplo: pato eles irão ler apenas as letras PA, P (PA) A (TO), pois ainda usam uma marca para denominar uma sílaba sonora (Kaufman et al., 1998).

Com o tempo, as escritas produzidas vão se adequando e começam a construir-se com base da análise silábica, até que a sílaba chegue a sua existência mais correta, que é quando começa a antecipar sistematicamente, antes de casa escrita, a quantidade de letras em função da quantidade de sílabas. No eixo qualitativo começam a aparecer as letras conforme o seu valor sonoro adequado "No mesmo período, ainda que não necessariamente ao mesmo tempo, as letras podem começar a adquirir valores sonoros silábicos relativamente estáveis, o qual conduz a estabelecer correspondências sobre o eixo quantitativo: as partes sonoras similares entre as palavras começam a expressar-se por letras similares" (Ferreiro, op. cit. p.16 apud Kaufman et al., 1998).

Portanto, depois de alfabetizada aparecem outros problemas, como a questão ortográfica, gramática. Caracteriza-se pela correspondência entre fonemas e grafemas, quando a criança compreende a organização da escrita e começa a perceber que cada emissão sonora pode ser representada, na escrita, por uma ou mais letras A criança embora alfabetizada, ainda pode escrever foneticamente (como se pronuncia a palavra), registrando os sons da fala, sem considerar as normas ortográficas da escrita e a segmentação (Ferreiro; Teberosky, 1986 apud Silva; Farago, 2016). 


\subsection{A importância da formação do professor para o ensino da língua escrita}

A partir dessa linha de pesquisa, mostra-se a importância de todo professor alfabetizador ter os conhecimentos básicos para exercer sua profissão de maneira positiva e obter sucesso. A formação continuada é um dos meios pelos quais, os professores podem procurar mais informações e conhecimentos para complementar sua carreira e tornar o ensino de "alfabetização" mais brando e positivo.

Como Weisz (2000) apresenta todo professor pode proporcionar uma boa situação de aprendizagem, que é o resultado de atividades planejadas e com a ajuda/intervenção pedagógica do professor para incentivar a aprendizagem dos alunos, por isso a importância dos conhecimentos e da formação para alfabetização. As propostas devem ser planejadas, os desafios ajustados às possibilidades de aprender dos alunos e questões sobre a escrita.

A autora apresenta quatro princípios básicos para que seja possível uma boa situação de aprendizagem, que são:

1) Os alunos precisam por em jogo tudo o que sabem e pensam sobre o conteúdo em torno do qual o professor organizou a tarefa. 2) Os alunos tem problemas a resolver e decisões a tomar em função do que se propõem a produzir. 3) O conteúdo trabalhado mantém suas características de objeto sociocultural real por isso, no caso da alfabetização, a proposta é o uso de textos, e não de sílabas ou palavras soltas. 4) A organização da tarefa garante a máxima circulação de informação possível entre os alunos por isso, as situações propostas devem prever o intercambio, a interação entre eles (Weisz, 2000, p. 66).

Os dois primeiros dão uma visão de como o sujeito constrói seu próprio conhecimento e requer das atividades colocadas uma situação desafiadora, que ao mesmo tempo é difícil mais possível ao aluno realizá-la. O conhecimento é obtido através da resolução desses problemas colocados pelo professor, criando uma superação de desafios, levando o sujeito ao qual é destinada a aprendizagem, a uma modificação de seus esquemas interpretativos, pois os disponíveis no momento não são suficientes para poder resolver tal problema. Portanto essas modificações não ocorram facilmente, é preciso que haja o sentimento de necessidade do cumprimento da atividade, pois, aprendemos à medida que os desafios colocados obrigam a pensar, a reorganizar o conhecimento que temos, a buscar mais informação, a refletir para busca de novas respostas (WEIZ, 2000).

Já o terceiro princípio destaca que a alfabetização é um processo de construção de hipóteses sobre o funcionamento e a regras do sistema alfabético da escrita, por isso não se pode usar da memorização para alfabetizar, mas sim, a reflexão sobre a escrita. O quarto princípio coloca que é preciso conhecer seus alunos e o que eles sabem para poder planejar bons agrupamentos. Para poder organizar agrupamentos produtivos, é preciso criar um desafio ajustado às necessidades de aprendizagem dos alunos, os agrupamentos planejados criteriosamente, as intervenções realizadas durante a realização da tarefa proposta ocasionam uma boa situação de aprendizagem (Weiz, 2000).

Uns dos maiores desafios para o professor, ao planejar as atividades, é pensar o que seus alunos sabem e pensam ajustando suas propostas, é necessário saber que a diversidade em uma sala de aula é inevitável, sempre haverá aluno com mais dificuldades e com facilidades na compreensão e por isso deve conhecer, analisar e acompanhar o que eles produzem.

Para organizar uma boa situação de aprendizagem o professor precisa ter clareza dos quatro princípios destacados por Weisz, (2000), sendo importante antes de preparar ou concluir uma proposta de atividade, se perguntar: a atividade proposta tem desafio? Qual? Para quem? E assim desenvolver a atividade com o intuito de oportunizar uma boa situação de aprendizagem.

Com base nos períodos que foram apresentados acima, pode-se fazer variações para alunos de outros níveis, como para o sílábico- alfabético retirando o banco de palavras para que o mesmo preencha os quadrinhos com as letras que completam o nome do desenho com o desafio de pensar em quais letras são utilizadas para escrever determinado nome. Importante nesse trabalho é o agrupamento, a troca de saberes, como citado no quarto princípio.

Outro aspecto importante que deve ser considerado: os alunos têm saberes diferente é importante considerar a 
heterogeneidade possibilitando que saberes sejam compartilhados, discutidos, confrontados e modificados, com propostas de atividades que ora serão iguais e ora haja variações, permitindo que cada aluno possa fazer novas descobertas (Zunino; Pizani, 1995).

Os alunos aprendem com a interação, por isso, é importante planejar as situações de aprendizagens para que na hora de trabalhar com agrupamentos eles realmente sejam positivos, e possam proporcionar a troca de pontos de vista, negociar e chegar a um acordo são situações necessárias dentro da sala de aula. Deixando assim, o professor de ser o único a trazer e passar informações onde os alunos começam a ajudar uns aos outros. Para organizar os agrupamentos na alfabetização, o professor precisa conhecer todas as características de seus alunos e o que já conhecem sobre a escrita. Uma boa sugestão é o uso de um caderno para anotar tudo o que for relevante como o desempenho e comportamento de seus alunos diante da escrita.

Deve-se considerar que naturalmente haja conflitos em um agrupamento, por isso, o professor deve preocupar-se em garantir atividades desafiadoras que carregam em si um problema a ser resolvido, para então, ao tentarem solucionar os alunos coloquem em prática o que já sabem e ajudem um ao outro, havendo uma progressão em seu processo de alfabetização, mesmo não contando com a intervenção direta do próprio professor. Não se devem deixar de lado as atividades individuais, pois, também são importantes durante qualquer processo de aprendizagem, pois os alunos também precisam de espaço para que possam trabalhar com suas próprias ideias.

Ao perceber as diferenças entre os saberes dos alunos, a intervenção deve-se dar de maneira diferenciada entre todos, diversificando os tipos de ajuda, como propor perguntas que requeiram níveis de esforço diferentes; oferecer uma informação específica que promova o estabelecimento de novas relações; ouvir o que o aluno tem a dizer sobre o que pensou para chegar a um determinado produto; estimular o progresso pessoal (Zunino; Pizani, 1995).

Para haver prioridade da cooperação entre os alunos em uma sala de aula, é necessário o respeito às idéias e maneiras de ser dos parceiros, a solidariedade, a justiça, o professor precisa atuar de acordo com esses princípios demonstrando em sala de aula tais princípios, criando um ambiente que demonstre os valores a serem ensinados.

Em todo processo é preciso que o professor assuma a condição de autor da própria prática pedagógica, que diante de cada situação, precisa refletir para buscar suas próprias soluções, construir novas estratégias, tomar decisões e ter uma autonomia intelectual. Para que tudo isso seja possível, é preciso uma reflexão sobre sua própria ação, auto-avaliação, trabalho em parceria, intencionalidade e como ponto principal a disponibilidade para aprender e experimentar.

Portanto, precisamos entender que o conhecimento é obtido através de estudos específicos e reconhecer a importância da formação continuada, para que assim, possamos encontrar um desempenho melhor no âmbito da alfabetização para que futuramente o índice de analfabetos diminua e haja mais contribuições para as aprendizagens de nossas crianças.

\section{Considerações Finais}

Este trabalho abordou conhecimentos sobre a Psicogênese da Língua Escrita e a importância da formação do professor, sabendo-se que a aquisição da leitura e da escrita também é uma ciência que deve ser trabalhada a partir de reflexões acerca da construção do saber, o ato de ensinar pode apresentar os mais amplos desafios para os professores, recorrendo à necessidade de um pensamento e repensamento sobre como exercer sua prática diante dos enfretamentos encontrados durante o percurso.

Conclui-se que a pesquisa realizada por Ferreiro e Teberosky (1999) trouxe várias contribuições para a o campo amplo da alfabetização, trazendo uma revolução nos conceitos que antigamente eram utilizados na alfabetização como o método de codificação e decodificação, que não eram métodos condizentes com as necessidades que encontrariam no seu percurso de aprendizagem, melhorando o trabalho prático com a aquisição da língua escrita nas escolas.

Buscou-se compreender de maneira mais ampla os estudos sobre a Psicogênese da Língua Escrita, apresentando como 
acontece esse desenvolvimento e os processos enfrentados pela criança ao passar por ele, buscando dessa forma mostrar a importância de um aprofundamento na área para alfabetização, sabendo que o professor precisa ser um pesquisador e procurar sempre compreender a necessidade do aluno, por isso a importância de uma formação continuada.

Pode-se dizer que o trabalho contribuiu para a ampliação de conhecimentos no que diz respeito à prática pedagógica do professor alfabetizador, esse profissional que precisa ter um olhar diferenciado para sua prática, uma prática voltada para aprendizagem do aluno. O que ele é capaz de fazer diante da atividade proposta pelo professor.

Para isso, o professor ao planejar suas atividades, deve pensar e refletir nos desafios que a atividade traz e em quem é capaz de resolvê-los, assumindo a responsabilidade ativa do levantamento de questões acerca do que ensinam como devem ensinar e quais são as metas mais importantes pelo qual, lutam para que de certo. Portanto, a relevância da formação do professor é essencial para o desenvolvimento de práticas alfabetizadoras conscientes.

Toda essa prática beneficia o aprendizado, pois garante organizar para o aprendiz situações de aprendizagem ajustadas às suas necessidades e contribui para a reflexão sobre a prática do professor diante de todas as alternativas, que é convidado a refletir toda e qualquer situação de aprendizagem proposta em sala de aula para que aprendizagens significativas aconteçam.

\section{Referências}

Bortolini, R. W., Miranda, V., \& Borssoi, B. L. (2015). Métodos de Aquisição da Leitura e da escrita: Reflexões sobre suas implicações na prática escolar. In: XII Congresso Nacional de Educação. <http://educere.bruc.com.br/arquivo/pdf2015/22602_11414.pdf/>.

Duarte, K., Rossi, K., \& Rodrigues, F. (2008). O processo de alfabetização da criança segundo Emilia Ferreiro. Revista Cientifica eletrônica de Pedagogia. Ano VI, 11, http://www.educadores.diaadia.pr.gov.br/arquivos/File/2010/artigos_teses/2010/Pedagogia/aprocesso_alfab_ferreiro.pdf/>.

Ferreiro, E. (2003). Cultura escrita e educação. CENP. Secretaria de Estado da Educação. Programa Letra e Vida. Coletânea de textos. Módulo 1, Unidade 4, Texto 5. São Paulo.

Ferreiro, E, \& Teberosky, (1998). A. Psicogênese da língua escrita. Tradução de Diana Myriam Lichtenstein, Liana Di marco e Mário Corso. (4a ed.), Artmed.

Kaufman, A. M. et al. (1998). Alfabetização de crianças: construção intercâmbio. Experiências Pedagógicas na Educação Infantil no Ensino Fundamental. (7a ed.), Artmed.

Mello, M. C. O. (2003). O pensamento de Emilia Ferreiro sobre alfabetização. Revista eletrônica: Acolhendo a Alfabetização nos Países de Língua Portuguesa. <https://www.revistas.usp.br/reaa/article/viewFile/11461/13229/>

Mendonça, O. S. (2000). Percurso Histórico dos métodos de alfabetização. In: Universidade Estadual Paulista Júlio de Mesquita Filho. UNESP. Presidente Prudente. <https://acervodigital.unesp.br/bitstream/123456789/40137/1/01d16t02.pdf>.

Mendonça, O. C. de, (2011). Psicogênese da Língua Escrita: contribuições, equívocos e consequências para a alfabetização. Cultura Acadêmica. 2, 36-57. (D16 - Conteúdo e Didática de Alfabetização). <http://acervodigital.unesp.br/handle/123456789/40138>.

Moreira, C. M. (2009). Os estágios de aprendizagem da escritura pela criança: uma nova leitura para um antigo tema. Linguagem em (Dis) curso. 9(2), 359$385,<$ http://www.scielo.br/pdf/ld/v9n2/07.pdf/>.

Moreira, G. E. (2014). O processo de alfabetização e as contribuições de Emília Ferreiro. Revista de Letras, 7(1) <https://portalrevistas.ucb.br/index.php/RL/article/viewFile/5041/3838/>

Mortatti, M. R. L. (2006). História dos métodos de alfabetização no Brasil. In: Conferência proferida durante o Seminário Alfabetização e Letramento em debate, promovido pelo Departamento de Políticas de Educação Infantil e Ensino Fundamental da Secretaria de Educação Básica do Ministério da Educação Básica do Ministério da Educação, realizado em Brasília, em 27/04/2006.

Oliveira, M. A. (2011). A observação e a intervenção na construção dos saberes e no processo de aquisição da escrita. In: I seminário internacional de representações sociais, subjetividade e educação- Sirsse. Pontifícia universidade católica do Paraná - Curitiba, 7 a 10 de novembro. <http://educere.bruc.com.br/CD2011/pdf/5417_3298.pdf>.

Santos, E. E. (2013). Alfabetização: o texto no processo inicial de aquisição da língua escrita. Revista Eletrônica de Educação de Alagoas. 1(1). <http://www.educacao.al.gov.br/component/jdownloads/send/151-1-edicao/547alfabetizacao-o-texto-no-processo-inicial-de-aquisicao-da-escrita?option=com_ jdownloads/>.

Silva, F. A, \& Farago, A. C. (2016). Psicogênese da Língua Escrita: contribuições e equívocos. Cadernos de Educação: Ensino e Sociedade, Bebedouro/SP. <http://unifafibe.com.br/revistasonline/arquivos/cadernodeeducacao/sumario/40/3004201610 4525.pdf/>

Weisz, T. (1988). As contribuições da Psicogênese da Língua Escrita e algumas reflexões sobre a prática educativa de alfabetização. Publicado pela secretaria da Educação do Estado de São Paulo em Ciclo Básico em Jornada Única: uma nova Concepção de Trabalho Pedagógico. São Paulo, FDE, 1988.

Weisz, T. (2000). O diálogo entre o ensino e a aprendizagem. (2a ed.), Ática.

Zunino, D. L., \& Pizani, A. P. (1995). A aprendizagem da língua escrita na escola. Artmed. 